\title{
Fibroblast Growth Factor Enhances Long-term Potentiation in the Hippocampal Slice
}

\author{
Heinrich Terlau and Wilfried Seifert \\ Max-Planck-Institut für biophysikalische Chemie, Department of Neurobiology, P.O. Box, D-3400 Göttingen, FRG
}

Key words: neuronal plasticity, neuromodulation, rat hippocampus

\begin{abstract}
Recently we reported that perfusion of hippocampal slices with epidermal growth factor (EGF) lead to enhancement of potentiated responses after tetanic stimulation. In the present study we report that basic fibroblast growth factor (FGF) can also lead to an enhancement of potentiated responses. FGF is a mitogen for several cell types and exhibits neurotrophic effects on neurons of the central nervous system (CNS). Rat hippocampal slices were perfused with FGF at a concentration of $10^{-9} \mathrm{M}$. During extra- and intracellular recordings in the $\mathrm{CA}_{1}$-region, the addition of FGF to the perfusing medium produced no change in evoked responses if single pulse or paired pulse stimulation was used. Furthermore FGF had no influence on the resting membrane potential and input resistance. However, after tetanic stimulation, FGF-treated slices showed an increase in the magnitude of potentiation compared to control slices. Taken together with the EGF data these results support the hypothesis that growth factors like FGF with neurotrophic potential on CNS-neurons can influence synaptic efficacy. Furthermore these results show that factors which are able to modulate developmental plasticity and regenerative plasticity can also modulate synaptic plasticity.
\end{abstract}

\section{Introduction}

Basic fibroblast growth factor (FGF) is a polypeptide originally identified in extracts of bovine pituitary (Gospodarowicz, 1974, 1975). It has been recognized as a mitogen for a variety of cells including astroglial cells (for review see: Gospodarowicz et al., 1986). More recently it has been shown that FGF exhibits neurotrophic effects on hippocampal (Walike et al., 1986) and cortical (Morrison et al., 1986) cells in culture. FGF has been isolated from brain (Gospodarowicz et al., 1984). Using a monoclonal antibody against astroglial growth factor (AGF, identical with FGF) FGF was found only in the neuronal cells of the brain and cerebellum (Pettmann et al., 1986, 1987). FGF appears early in brain development and then remains throughout adulthood.

Long-term potentiation (LTP) is an increase in synaptic strength induced by brief repetitive stimulation. This increase in synaptic strength lasts for many hours and, in the intact animals, even for weeks (Bliss and Lømo, 1973; Bliss and Gardner-Medwin, 1973). It has been suggested that neurite-inducing factors are released during tetanic stimulation and that these substances are involved in LTP (Sastry et al., 1988). Recently we showed that treatment with epidermal growth factor (EGF) leads to an enhancement in LTP after tetanic stimulation (Terlau and Seifert, 1988, 1989a). EGF is also a mitogen for several cell types. It has been shown that EGF has neurotrophic effects on neurons of the central nervous system (CNS) with some differences relative to FGF (Morrison et al., 1988; Seifert and Förster, unpublished observation). Our previous observation that EGF enhanced LTP led us to investigate whether other growth factors with neurotrophic potential may modulate synaptic plasticity. Since not all polypeptide growth factors exhibit neurotrophic action on neurons of the CNS (Morrison et al., 1986), in the present study possible effects of FGF on LTP were investigated. Some of these results have been published in abstract form (Terlau and Seifert, 1989b).

\section{Materials and methods}

\section{Slice preparation}

Transverse hippocampal slices were prepared from 8-12 week old Wistar rats $(200-300 \mathrm{~g})$ bred in the Max-Planck-Institute. Following decapitation, the brain was removed from the skull and both hippocampi were dissected out. Slices ( $400 \mu \mathrm{m}$ thick) were cut with a tissue chopper and placed directly in one of two recording chambers and kept at $33 \pm 0.5^{\circ} \mathrm{C}$. The whole preparation procedure was performed in oxygenated, ice cooled Ringer's solution. The slice chamber (after Langmoen and Andersen, 1981; modified by $\mathrm{H}$. Terlau) was constantly aerated with $5 \% \mathrm{O}_{2}-95 \% \mathrm{CO}_{2}$ and Ringer's solution was perfused continuously through both recording chambers at a rate of $0.8-1.0 \mathrm{ml} / \mathrm{min}$. The composition of the Ringer's solution was (mM): $\mathrm{NaCl} 124, \mathrm{KCl} 5.0, \mathrm{KH}_{2} \mathrm{PO}_{4} 1.25, \quad \mathrm{MgSO}_{4} \times 7 \mathrm{H}_{2} \mathrm{O} 2.0$, $\mathrm{CaCl}_{2} \times 2 \mathrm{H}_{2} \mathrm{O} 3.0, \mathrm{NaHCO}_{3} 26$, D-glucose 10 . 


\section{Electrophysiology and data analysis}

After a preincubation period $(1.5 \mathrm{~h})$ slices to be used for recording were transferred into the second recording chamber. A bipolar stimulation electrode (tungsten in glass) was placed in the stratum radiatum of the $\mathrm{CA}_{3}$-region of the slice. Stimuli consisted of a constant current pulse of $0.05 \mathrm{~ms}$ duration and were delivered at $0.1 \mathrm{~Hz}$ at all times except high frequency stimulation $(1 \times 100 \mathrm{~Hz}$ for $1 \mathrm{~s})$ to induce LTP. In the intracellular studies paired pulses with an interval of $55 \mathrm{~ms}$ were applied.

Extra-or intracellular records were taken in the $\mathrm{CA}_{1}$ cell body layer. A second extracellular recording electrode was placed in the stratum radiatum of the $\mathrm{CA}_{1}$-region. The recording electrodes were either filled with $2 \mathrm{M} \mathrm{NaCl} \mathrm{(4-12} \mathrm{M \Omega )} \mathrm{or} \mathrm{filled} \mathrm{with} 4 \mathrm{M}$ KAc (30$60 \mathrm{M} \Omega$ ). Only slices which showed clearly visible evoked responses with a stimulation strength below $500 \mu \mathrm{A}$ were used in further analysis.

In the experiments where LTP was induced and FGF was added before tetanic stimulation, adjacent slices were separated into matched pairs (control-slice, FGF-slice) and recording of the two slices were performed one after the other. The stimulus strength in these experiments was adjusted in such a way that before the tetanus was given the evoked responses in control- and FGF-treated slices were quite similar: Population spike amplitude: control: $4.27 \pm 0.37 \mathrm{mV}$, FGF: $4.55 \pm 0.47 \mathrm{mV}$; field excitatory postsynaptic potential (EPSP) slope: control: $3.00 \pm 0.24 \mathrm{mV} / \mathrm{ms}$, FGF: $3.02 \pm 0.27 \mathrm{mV} / \mathrm{ms}$; mean $\pm \mathrm{SEM} ; n=20$ pairs. The stimulus strength used in these experiments was: control: $167 \pm 9 \mu \mathrm{A}$, FGF: $172 \pm 12 \mu \mathrm{A}$. In order to achieve equivalent conditions in both slices an effort was made to position the electrodes similarly, especially with respect to the distance (Dingledine et al., 1987).

Population spike amplitudes were defined as the amplitude from the negative peak to the late positive peak. The field EPSP slopes were calculated from the initial negative slope of the field potential using a form of linear regression.

For intracellular recording an impaled neuron was accepted when it had no spontaneous discharges and a membrane potential below $-60 \mathrm{mV}$. The input resistances of the cells were measured using a hyperpolarizing current pulse $(15 \mathrm{~ms}, 0.5 \mathrm{nA})$ applied through the recording electrode. In these experiments the stimulus strength used was subthreshold so that no spike was seen. EPSP amplitudes were measured baseline to peak.

Evoked potentials were stored on a lab computer based on an LSI 11/73. During extracellular recordings 6 or 12 sweeps were averaged on line. During intracellular recordings single sweeps were stored. In these experiments only every second sweep was stored to reduce the amount of data. To compare the amplitudes of the evoked EPSPs before addition and $20 \mathrm{~min}$ afterwards, 10 sweeps at these time points were averaged off line. Further off line data analysis was done with a $\mu$ VaxII.

\section{Fibroblast growth factor}

Lyophilized FGF from bovine pituitary glands (Sigma, after Gospodarowicz, 1975) was first diluted in distilled water and aliquots stored at $-20^{\circ} \mathrm{C}$. The biological activity of the used batch of FGF was tested in a bioassay for survival and neurite outgrowth in our hippocampal cell culture system (Seifert et al., 1983).

For each experiment one aliquot was taken and added to Ringer's solution to a final FGF-concentration of $10^{-9} \mathrm{M}$. Perfusion of the slices with this Ringer's solution containing FGF was only started after stable evoked potentials (either field potentials or EPSPs) were seen.
When tetanic stimulation was applied, perfusion with FGF was started 20 min before the tetanus.

\section{Results}

Perfusion of the slices $(n=5)$ with FGF up to 60 min has no effect on extracellular potentials evoked by single pulse stimulation in the $\mathrm{CA}_{1}$ region (Fig. 1). Furthermore there was no change in the
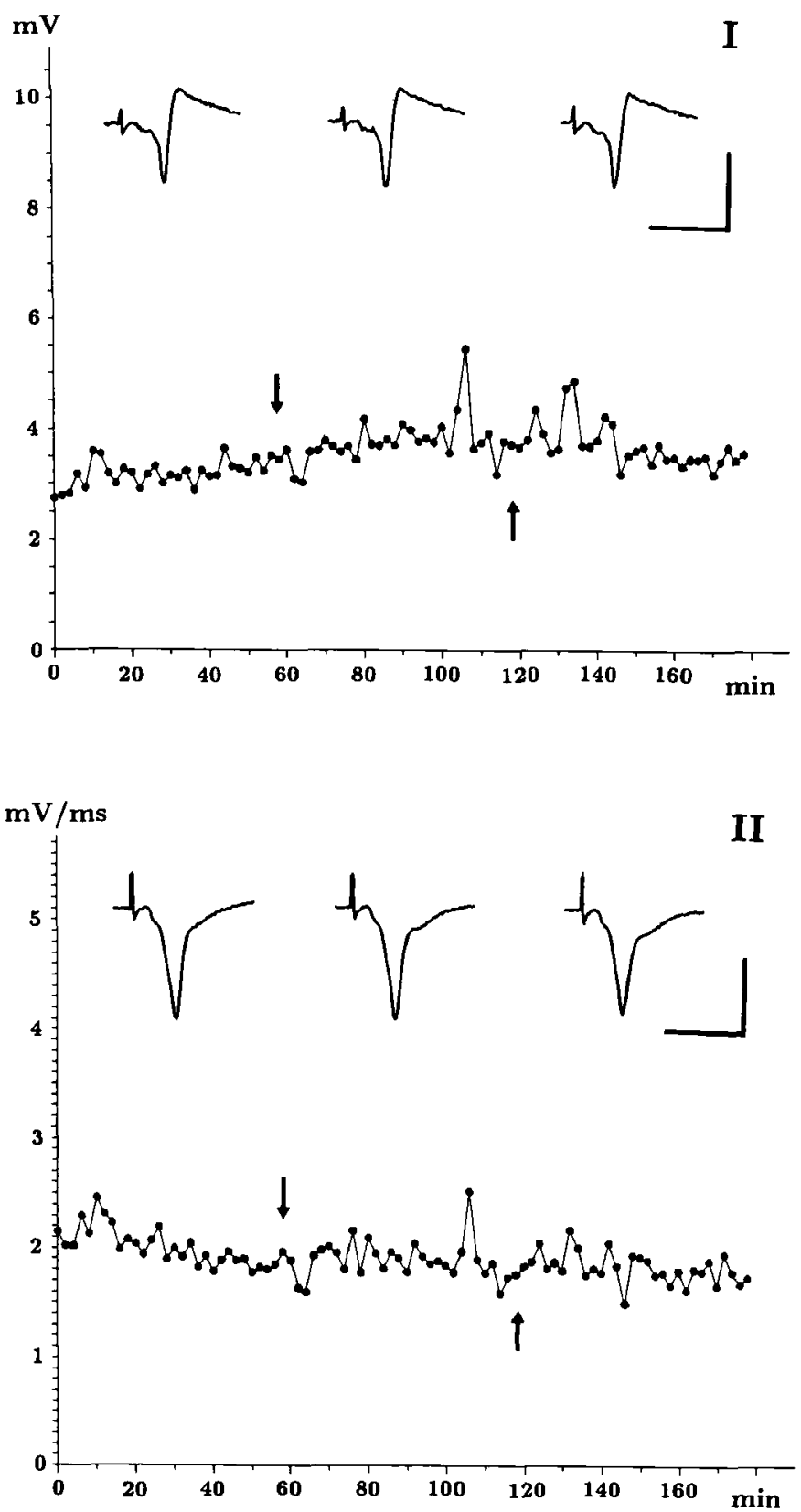

Fig. 1. Population spike and field EPSP during low frequency stimulation and FGF perfusion. (I) Upper panel: population spike before, during and after the addition of FGF; lower panel: changes in the size of the population spike with time. (II) Upper panel: field EPSP before, during and after addition of FGF; lower panel: changes of the slope of the field EPSP with time. At $\downarrow$ perfusion with Ringer's solution containing FGF was initiated. At $\uparrow$ the slice was perfused again with Ringer's solution. The calibration represents: $3 \mathrm{mV}, 10 \mathrm{~ms}$. 
amplitudes of the first and second EPSP in intracellular recording during paired pulse stimulation (Fig. 2). Before addition of FGF the average amplitude of the first EPSP was: $4.08 \pm 0.35 \mathrm{mV}$. The average of the EPSP amplitude $20 \mathrm{~min}$ later (the same time point at which the tetanus was given in the experiments concerning LTP) was: $4.14 \pm 0.43 \mathrm{mV}$ $(n=20$ cells, mean \pm SEM). Similar results were obtained in these experiments for the amplitude of the second EPSP. At the beginning of the perfusion with FGF the average amplitude of the second EPSP was: $9.14 \pm 0.54 \mathrm{mV}(n=20$ cells $)$ and $20 \mathrm{~min}$ afterwards the average amplitude was: $9.50 \pm 0.57 \mathrm{mV}(n=16$ cells, four cells produced action potentials and were discarded from analysis).

There was no influence of FGF on the resting membrane potential of the cells investigated. The average resting membrane potential at the beginning of the perfusion with FGF was: $-67.9 \pm 1.2 \mathrm{mV}$ and 20 min afterwards the cells had a resting membrane potential of $-68.8 \pm 1.2 \mathrm{mV}$ (mean $\pm \mathrm{SEM}$ ). Additionally, using short hyperpolarizing current pulses FGF was found to have no effect on the input resistance.

In contrast to these results FGF induced an increase in the magnitude of potentiation (Fig. 3). Directly after tetanization both control- and FGF-treated slices showed similar potentiation. However, after the tetanus was given the FGF-treated slices stayed at higher potentiation levels, while the control-slices showed a larger decay in the potentiated response. The increase in potentiation of the population spike amplitudes was not significant over the time investigated, but showed the same tendency of the potentiated dendritic responses of the FGF treated slices, which were clearly enhanced at later time points after tetanic stimulation (Fig. 3). For example 30 min after tetanic stimulation the increase in
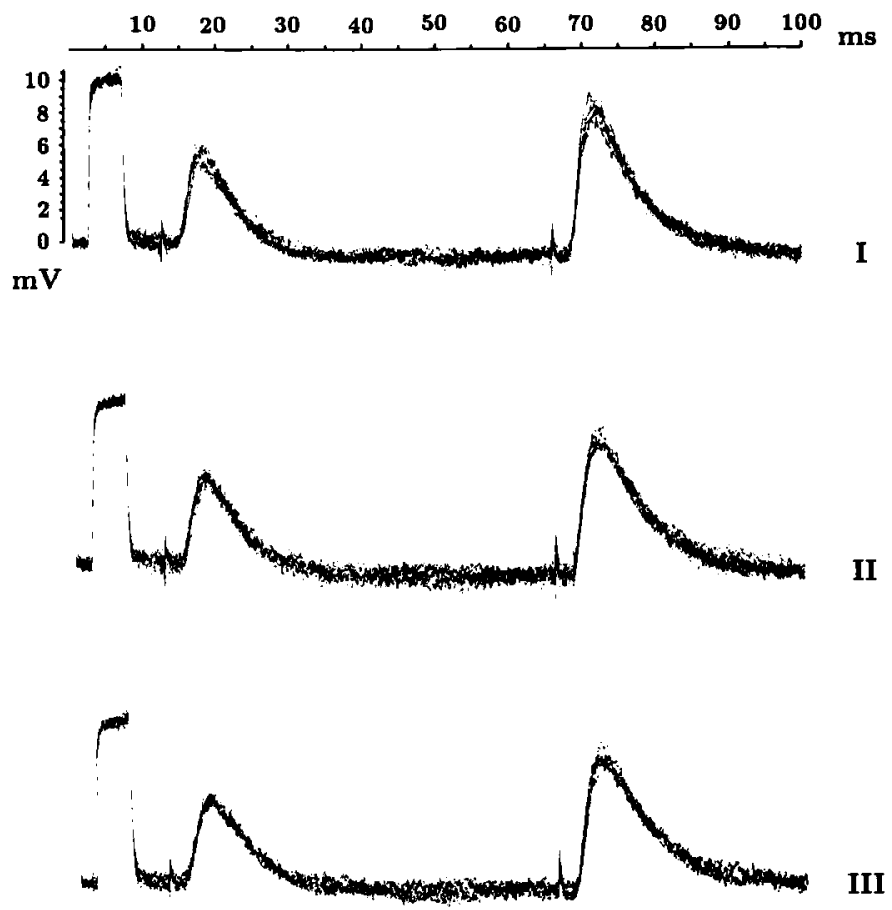

FIG. 2. EPSPs evoked by paired pulse stimulation before and after addition of FGF. (I) Single responses (10 sweeps) at the beginning with the perfusion of the FGF-containing Ringer's solution; (II) 20 min afterwards; (III) 40 min afterwards. The square wave pulse represents a calibration $(5 \mathrm{~ms}, 10 \mathrm{mV})$. Since every sweep is $20 \mathrm{~s}$ apart, both pictures represent $200 \mathrm{~s}$ of recording time. the field EPSP slope was $128 \pm 4.3 \%$ for the control slices and $144.0 \pm 5.3 \%$ (mean $\pm \mathrm{SEM}, n=20$ pairs, $P<0.01$ ) for the slices which had been perfused with FGF. We then raised the question of whether FGF also modulates LTP when added after tetanic stimulation. LTP was induced and 20 min later perfusion with FGF-containing Ringer's solution was initiated. As shown in Figure 4, perfusion of the slices for $30 \mathrm{~min}$ with FGF had no effect on the potentiated evoked potentials.

I

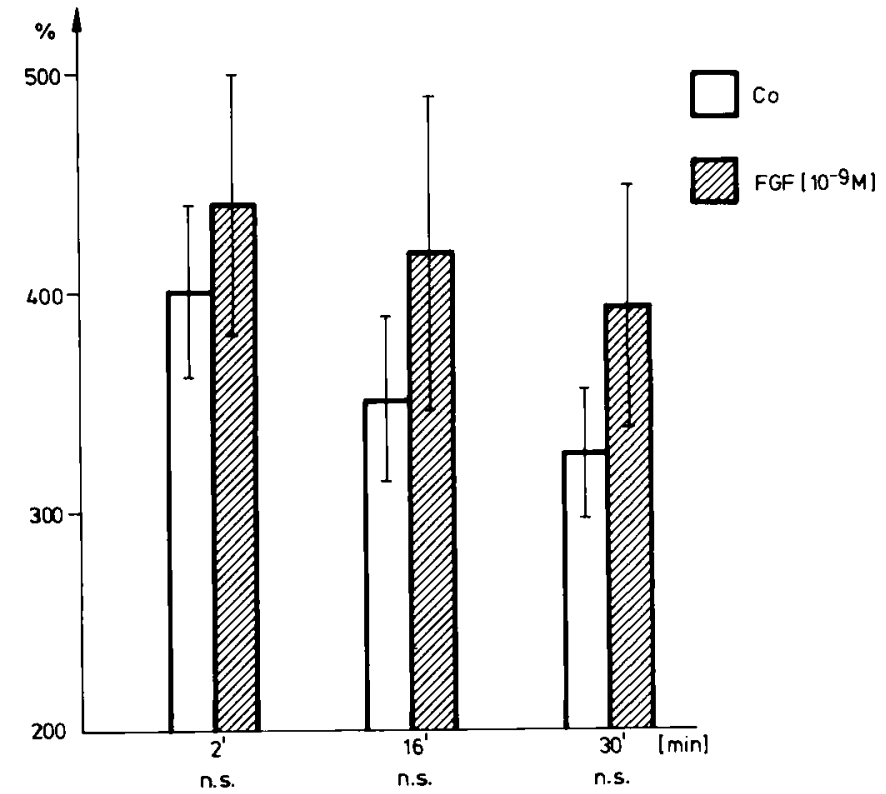

II

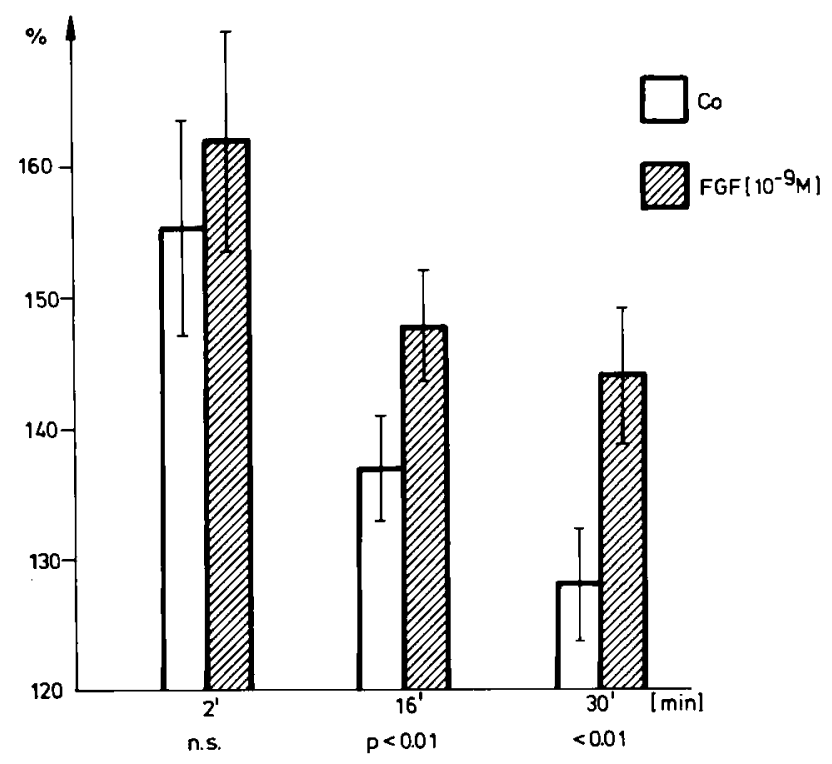

FIG. 3. Effect of FGF on LTP. (I) Potentiation of the population spike amplitude after tetanic stimulation. (II) Potentiation of the field EPSP slope after tetanic stimulation. $100 \%$ : average of the population spike amplitude or the field EPSP slope 10 min before tetanic stimulation; $n=20$ pairs of slices; Vertical bars: SEM; p-values: Wilcoxon signed rank test. 

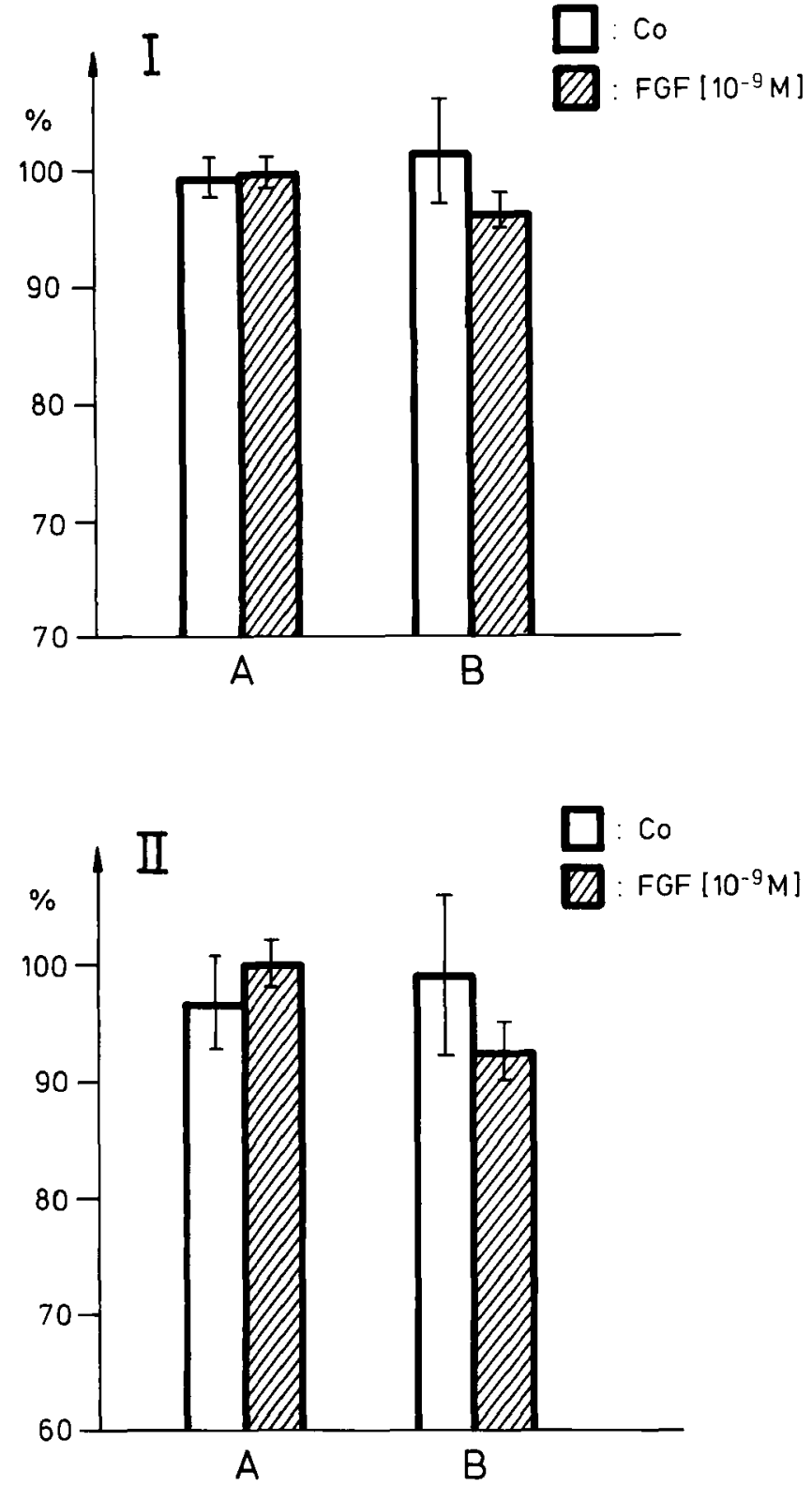

FIG. 4. Addition of FGF after tetanic stimulation. (I) Amplinude of the population spike at the beginning (A) with perfusion of FGF or Ringer's solution (control) and 30 min later (B). (II) Field EPSP slope at the beginning (A) with perfusion of FGF or Ringer's solution (control) and $30 \mathrm{~min}$ later (B). Given values are calculated from $3 \mathrm{~min}$ of recording time. $100 \%$ : average of the population spike amplitude or the field EPSP slope 5 min before perfusion with FGF or Ringer's solution (control) was initiated (corresponds to 15-20 min after tetanic stimulation); FGF: $n=7$; control: $n=6$; Vertical bars: SEM.

\section{Discussion}

Our results demonstrate that perfusion of hippocampal slices with FGF does not lead to changes in the excitability of the $\mathrm{CA}_{1}$-neurons if low frequency stimulation is applied as measured extracellularly by population spike and field EPSP. Furthermore no changes in the excitability were seen when paired pulse stimulation was given as measured intracellularly by resting membrane potential, input resistance and EPSP amplitudes. In contrast to this, an increase in LTP especially for the later time points after tetanic stimulation was observed. Therefore exogenously added FGF obviously can modulate LTP.

Interestingly, FGF does not lead to changes in the evoked potentials when it is added $20 \mathrm{~min}$ after tetanic stimulation. With this result it is very likely that processes which are activated during or in the first 20 min after tetanic stimulation are involved in the modulatory effect of FGF on LTP. Therefore it seems that the enhancement of FGF on LTP depends either on the strong depolarization during tetanic stimulation or on other processes activated at early time points after tetanic stimulation, such as activation of protein kinases (see below).

The presence of FGF in cell bodies and dendrites of the hippocampal $\mathrm{CA}_{1}$ area has been demonstrated by immunohistochemistry (Pettmann et al., 1987; Terlau, Flott and Seifert, unpublished). In spite of these observations, little is known about the activities of FGF in vivo. For example the site of synthesis and mechanisms of release of FGF have not been determined. FGF has been shown to activate protein kinase $\mathrm{C}$ in 3 T3 fibroblasts (Kaibuchi et al., 1986). Activation of protein kinase $\mathrm{C}$ is also probably important for the maintenance of LTP (Akers et al., 1986; Hu et al., 1987; Reymann et al., 1988; Malinow et al., 1989). Furthermore it is known that FGF leads to a rapid increase in c-fos and c-myc proto-oncogenes in 3 T3 cells (Müller et al., 1984). A possible involvement of proto-oncogenes in LTP has been discussed recently (Cole et al., 1989; Dragunow et al., 1989).

FGF as a growth factor is known to stimulate protein synthesis in non-neuronal cells (Rudland et al., 1974). It has also been demonstrated that protein synthesis is probably required for the maintenance of LTP (Krug et al., 1984; Stanton and Sarvey, 1984). Finally, changes in spine morphology as a consequence of LTP have been described (Fifkova and Harreveld, 1977; Andersen et al., 1987). Taken together all these observations suggest that perhaps similar molecular mechanisms are operating during developmental and synaptic plasticity. Interestingly it has been reported that FGF also has effects on regeneration of CNS neurons (Anderson et al., 1988). Therefore it may be possible that growth factors such as FGF play a role as modulators of several processes related to neuronal plasticity.

It is interesting that the described modulation of LTP by FGF differs in its time course from the effect of EGF on LTP. Addition of EGF leads to an enhancement in the potentiated responses directly after the tetanus was given (Terlau and Seifert, 1989a), whereas FGF affects only the potentiated responses at later time points after tetanic stimulation. The modulatory action of both growth factors on synaptic plasticity is a new aspect among the variety of described effects of growth factors, and may be of physiological relevance. Thus neurotrophic factors may not only control developmental and regenerative plasticity, but may also function as modulators of synaptic plasticity in the adult nervous system.

\section{Acknowledgements}

The authors thank Professor O. Creutzfeldt for his interest and support, and Professor M. Jackson for reading the manuscript.

\section{Abbreviations}

AGF astroglial growth factor

CNS central nervous system

EGF epidermal growth factor

EPSP excitatory postsynaptic potential

FGF fibroblast growth factor

LTP long-term potentiation 


\section{References}

Akers, R. F., Lovinger, D. M., Colley, P. A., Linden, D. J., and Routtenberg, A. (1986) Translocation of protein kinase C activity may mediate hippocampal long term potentiation. Science 231: 587-589.

Andersen, P., Blackstad, T., Hulleberg, G., Vaaland, J. L. and Tromvald, M. (1987) Changes in spine morphology associated with long-term potentiation in rat dentate granule cells. Proc. Physiol. Soc. 5P.

Anderson, K. J., Dam, D. , Lee, S. and Cotman, C. W. (1988) Basic fibroblast growth factors prevents death of lesioned cholinergic neurons in vivo. Nature 332: 360-361.

Bliss, T. V. P. and Gardner-Medwin, A. R. (1973) Long-lasting potentiation of synaptic transmission in the dentate area of the unanaesthetized rabbit following stimulation of the perforant path. J. Physiol. (Lond.) 232: 357-374.

Bliss, T. V. P. and Lomo, T. (1973) Long-lasting potentiation of synaptic transmission in the dentate area of the anaesthetized rabbit following stimulation of the perforant path. J. Physiol. (Lond.) 232: 331-356.

Cole, A. J., Saffen, D. W., Baraban, J. M. and Worley, P. F. (1989) Rapid increase of an immediate early gene messenger RNA in hippocampal neurons by synaptic NMDA receptor activation. Nature 340: 474-476.

Dingledine, R., Roth, A. A. and King, G. L. (1987) Synaptic control of pyramidal cell activation in the hippocampal slice preparation in the rat. Neuroscience 22: $553-561$.

Dragunow, M., Abraham, W. C., Goulding, M., Mason, S. E., Robertson, H. A. and Faul, R. L. M. (1989) Long-term potentiation and the induction of $c$-fos mRNA and proteins in the dentate gyrus of unanesthetized rats. Neurosci. Lett. 101: 274-280.

Fifkova, E. and van Harreveld, A. (1977) Long-lasting morphological changes in dendritic spines of dentate granule cells following stimulation of the entorhinal area. J. Neurocytol. 6: $211-230$.

Gospodarowicz, D. (1974) Localisation of a fibroblast growth factor and its effect alone and with hydrocortisone on 3T3 cell growth. Nature 249: $123-127$.

Gospodarowicz, D. (1975) Purification of a fibroblast growth factor from bovine pituitary. J. Biol. Chem. 250: 2515-2520.

Gospodarowicz, D., Cheng, J., Lui, G., Baird, A. and Bohlen, P. (1984) Isolation of brain fibroblast growth factor by heparin-sepharose affinity chromatography: Identity with pituitary fibroblast growth factor. Proc. Natl. Acad. Sci. USA 81: 6963-6967.

Gospodarowicz, D., Neufeld, G. and Schweigerer, L. (1986) Molecular and biological characterization of fibroblast growth factor, an angiogenic factor which also controls the proliferation and differentiation of mesoderm and neuroectoderm derived cells. Cell Diff. 19: 1-17.

Hu, G. Y., Hvalby, $\emptyset$., Walaas, S. I., Albert, K. A., Skieflo, P., Andersen, P. and Greengard, P. (1987) Protein kinase C injection into hippocampal pyramidal cells elicits features of long-term potentiation. Nature 328: $426-429$.

Kaibuchi, K., Tsuda, T., Kikuchi, A., Tanimoto, T., Yamashita, T. and Takai, Y. (1986) Possible involvement of protein kinase $C$ and calcium ion in growth factor-induced expression of c-myc oncogene in swiss 3T3 fibroblasts. J. Biol. Chem. 261: 1187-1192.

Krug, M., Lössner, B. and Ott, T. (1984) Anisomycin blocks the late phase of long-term potentiation in the dentate gyrus of freely moving rats. Brain Res. Bull. 13: $39-42$
Langmoen, I. A. and Andersen, P. (1981) The hippocampal slice in vitro. A description of the technique and some examples of the opportunities it offers. In: Kerkut, G. A. and Wheal, H. V. (eds), Electrophysiology of Isolated Mammalian CNS Preparations pp. 51-105. Academic Press, London.

Malinow, R., Schulman, H. and Tsien, R. W. (1989) Inhibition of postsynaptic PKC or CaMKII blocks induction but not expression of LTP. Science 245 : $862-866$.

Morrison, R. S., Sharma, A., de Vellis, J. and Bradshaw, R. A. (1986) Basic fibroblast growth factor supports the survival of cerebral cortical neurons in primary culture. Proc. Natl. Acad. Sci. USA 83: 7537-7541.

Morrison, R. S., Keating, R. F. and Moskal, J. R. (1988) Basic fibroblast growth factor and epidermal growth factor exert differential trophic effects on CNS neurons. J. Neurosci. Res. 21:71-79.

Müller, R., Bravo, R., Burckhardt, J. and Curran, T. (1984) Induction of c-fos gene and protein by growth factors precedes activation of $\mathrm{c}$-myc. Nature 312 : $716-720$.

Pettmann, B., Labourdette, G., Weibel, M. and Sensenbrenner, M. (1986) The brain fibroblast growth factor (FGF) is localized in neurons. Neurosci. Lett. 68: $175-180$.

Pettmann, B., Gensburger, C., Weibel, M., Perraud, F., Sensenbrenner, M. and Labourdette, G. (1987) Isolation of two astroglial growth factors from bovine brain; comparison with other growth factors; cellular localisation. In: Althaus, H. H. and Seifert, W. (eds), Glial-Neuronal Communication in Development and Regeneration, pp. 451-478. NATO ASI Series, Springer-Verlag., Berlin.

Reymann, K. G., Brödemann, R., Kase, H. and Matthies, H. (1988) Inhibitors of calmodulin and protein kinase $\mathrm{C}$ block different phases of hippocampal long-term potentiation. Brain. Res. 461: 388-392.

Rudland, P. S., Seifert, W. and Gospodarowicz, D. (1974) Growth control in cultured fibroblasts: Induction of the pleiotypic and mitogenic response by a purified growth factor. Proc. Natl. Acad. Sci. USA 71: 2600-2604.

Sastry, B. R., Chirwa, S. S., May, P. B. Y. and Maretić, H. (1988) Substances released during tetanic stimulation of rabbit neocortex induce neurite growth in PC-12 cells and long-term potentiation in guinea pig hippocampus. Neurosci. Lett. 91: 101-105.

Seifert, W., Ranscht, B., Fink, H. J., Förster, F., Beckh, S. and Müller, H. W. (1983) Development of hippocampal neurons in culture: a molecular approach. In: Seifert, W. (ed.), Neurobiology of the Hippocampus, pp. 109-135. Academic Press, London.

Stanton, P. K. and Sarvey, J. M. (1984) Blockade of long-term potentiation in rat hippocampal $\mathrm{CA}_{1}$ region by inhibitors of protein synthesis. $J$. Neurosci. 4: 3080-3088.

Terlau, H. and Seifert, W. (1988) Influence of EGF on long-term potentiation in the hippocampal slice. Abstracts 11 th Annual Meeting, European Neuroscience Association, 79.7.

Terlau, H. and Seifert, W. (1989a) Influence of epidermal growth factor on long-term potentiation in the hippocampal slice. Brain Res. 484: 352-356.

Terlau, H. and Seifert, W. (1989b) Influence of growth factors on synaptic plasticity: Differential effect of EGF and FGF on LTP in the hippocampal slice. Abstracts 19th Annual Meeting, Society of Neuroscience, 38.16.

Walike, P., Cowan, W. M., Ueno, N., Baird, A. and Guillemin, R. (1986) Fibroblast growth factor promotes survival of dissociated hippocampal neurons and enhances neurite extension. Proc. Natl. Acad. Sci. USA 83: 3012-3016. 